\title{
Über den Abbau des Coffeins durch den Auszug aus der Rinderleber.
}

\author{
Von \\ Prof. Y. Kotake.
}

(Aus der chemischen Abteilung des physiologischen Instituts der medizinischen Akademie zu Osaka, Japan.)

(Der Redaktion zugegangen am 26. August 1908.)

Über den Abbau des Coffeins zu Dimethylxanthin resp. Monomethylxanthin im tierischen Organismus sind wir bereits durch schöne Arbeiten von Manfredi Albanese ${ }^{1}$ ) und St. Bondzynski und R. Gottlieb ${ }^{2}$ ) unterrichtet worden. Diese Erscheinung läßt vermuten, daß es sich um die Wirkung irgend eines in den Organen produzierten Fermentes handelt, denn die neueren Untersuchungen haben ergeben, da $\beta$ die chemischen Vorgänge in den lebenden Zellen meist durch Fermente verursacht werden. Um die Richtigkeit dieser Deutung auf experimentellem Wege zu prüfen, habe ich die folgenden Versuche angestellt.

\section{Versuch I.}

$1800 \mathrm{~g}$ zerhackter Rinderleber wurden mit dem doppelten Volumen toluolhaltigen Wassers durchgerührt und nach 24stündigem Stehenlassen durch Leinwand koliert. Das Kolat wurde in zwei Portionen von je $1800 \mathrm{ccm}$ geteilt, die eine nach Zusatz von $9 \mathrm{~g}$ Coffein, die andere sofort bei Gegenwart von Toluol bei Körpertemperatur digeriert. Nach 4 tägiger Digestion wurden die beiden Portionen zur völligen Koagulation der Eiweißstoffe erhitzt und filtriert. Das Filtrat wurde mit Bleiessig gefällt, filtriert, durch Schwefelwasserstoff vom über-

1) M. Albanese, Arch. f. exp. Pathol. u. Pharmakol., Bd. XXXV, S. 449 .

2) St. Bondzynski und R. Gottlieb, Archiv f. exp. Pathol. u. Pharmakol., Bd. XXXVI, S. 45. 
Über den Abbau des Coffeins durch den Auszug aus Rinderleber. 379

schüssigen Brei befreit und auf ein kleines Volumen auf dem Wasserbade eingedampft. Die so eingeengte Flüssigkeit wurde mit Ammoniak übersättigt und mit ammoniakalischer Silberlösung vollständig ausgefällt; der Niederschlag wurde durch gründliches Auswaschen mit Wasser vom Ammoniak befreit, mit Salzsäure übergossen, 24 Stunden lang stehen gelassen, filtriert und das Filtrat zur Trockene verdampft. Ich bestimmte nun den Gehalt dieses Rückstandes an Stickstoff nach der Methode von Kjeldahl. Ich will diesen Stickstoff kurz als *Purinstickstoff » bezeichnen.

Die gewonnenen Resultate sind in der folgenden Tabelle zusammengestellt.

Tabelle 1.

\begin{tabular}{c|c|c|c}
\hline \hline $\begin{array}{c}\text { Dauer der } \\
\text { Digestion }\end{array}$ & $\begin{array}{c}\text { Menge des } \\
\text { Leberextraktes } \\
\text { in ccm }\end{array}$ & $\begin{array}{c}\text { Zugefügtes } \\
\text { Coffein } \\
\text { in } g\end{array}$ & $\begin{array}{c}\text { Menge des } \\
\text { gefundenen \&Purin- } \\
\text { stickstoffes } \\
\text { in g }\end{array}$ \\
\hline $\begin{array}{c}4 \text { Tage } \\
4,\end{array}$ & $\begin{array}{c}1800 \\
1800\end{array}$ & - & 0,0874 \\
\end{tabular}

Versuch 2.

$1000 \mathrm{~g}$ Leberbrei wurden mit dem doppelten Volumen toluolhaltigen Wassers versetzt und nach 24 stündigem Stehenlassen koliert. Vom Kolate wurden zwei Portionen zu $1000 \mathrm{ccm}$ abgemessen, die eine nach Zusatz von $5 \mathrm{~g}$ Coffein, die andere sofort zur Digestion angesetzt. Nach 4 tägiger Digestion wurden die beiden Portionen auf die gleiche Weise behandelt, wie im Versuche I.

Die erhaltenen Resultate sind in der folgenden Tabelle zusammengestellt.

Tabelle 2.

\begin{tabular}{c|c|c|c}
\hline $\begin{array}{c}\text { Dauer der } \\
\text { Digestion }\end{array}$ & $\begin{array}{c}\text { Menge des } \\
\text { Leberextraktes } \\
\text { in ccm }\end{array}$ & $\begin{array}{c}\text { Zugefügtes } \\
\text { Coffein } \\
\text { in } g\end{array}$ & $\begin{array}{c}\text { Menge des } \\
\text { gefundenen Purin- } \\
\text { stickstoffes } \\
\text { in } \mathbf{g}\end{array}$ \\
\hline $\begin{array}{c}4 \text { Tage } \\
4,\end{array}$ & 1000 & 5 & 0,0325 \\
1000 & - & 0,0196
\end{tabular}


Versuch 3.

Der Leberauszug, welcher aus $600 \mathrm{~g}$ Leberbrei und $1200 \mathrm{ccm}$ Wasser bereitet war, wurde koliert und dann durch Papier filtriert. Vom Filtrate wurden zwei Portionen zu $600 \mathrm{ccm}$ abgemessen, die eine nach Zusatz von $3 \mathrm{~g}$ Coffein, die andere sofort in den Brutschrank gestellt. Nach 4 tägiger Digestion wurden die beiden Portionen zur Bestimmung des Purinstickstoffes verwendet.

Die gewonnenen Resultate sind in der folgenden Tabelle zusammengestellt.

Tabelle 3.

\begin{tabular}{c|c|c|c}
\hline \hline $\begin{array}{c}\text { Dauer der } \\
\text { Digestion }\end{array}$ & $\begin{array}{c}\text { Menge des } \\
\text { Filtrates vom } \\
\text { Leberauszug } \\
\text { in ccm }\end{array}$ & $\begin{array}{c}\text { Zugefügtes } \\
\text { Coffein } \\
\text { in } \mathrm{g}\end{array}$ & $\begin{array}{c}\text { Menge des } \\
\text { gefundenen Purin- } \\
\text { stickstoffes } \\
\text { in g }\end{array}$ \\
\hline $\begin{array}{c}\text { 4 Tage } \\
4 \text { S }\end{array}$ & 600 & 3 & 0,0097 \\
600 & - & 0,0036
\end{tabular}

Versuch 4 .

Der Leberauszug, welcher aus $1500 \mathrm{~g}$ Leberbrei und $3000 \mathrm{ccm}$ Wasser bereitet war, wurde zum Sieden erhitzt und nach dem Erkalten in zwei Anteile von je $1500 \mathrm{ccm}$ geteilt, der eine nach Zusatz von 7,5 g Coffein, der andere sofort bei Bruttemperatur digeriert. Nach 4 tägiger Digestion wurde Purinstickstoff in den beiden Anteilen nach dem oben beschriebenen Verfahren bestimmt.

Die gewonnenen Resultate sind in der folgenden Tabelle zusammengestellt.

Tabelle 4 .

\begin{tabular}{c|c|c|c}
\hline $\begin{array}{c}\text { Dauer der } \\
\text { Digestion }\end{array}$ & $\begin{array}{c}\text { Menge des } \\
\text { gekochten Leber- } \\
\text { extraktes } \\
\text { in ccm }\end{array}$ & $\begin{array}{c}\text { Zugesetztes } \\
\text { Coffein } \\
\text { in g }\end{array}$ & $\begin{array}{c}\text { Menge des } \\
\text { gefundenen Purin- } \\
\text { stickstoffes } \\
\text { in g }\end{array}$ \\
\hline $\begin{array}{l}4 \text { Tage } \\
4 \text { \& }\end{array}$ & 1500 & 7,5 & 0,0193 \\
1500 & - & 0,0189
\end{tabular}


Über den Abbaa des Coffeins durch den Auszug aus Rinderleber. 381

Aus den geschilderten Versuchen, die mehrfach wiederholt wurden und stets in der gleichen Weise ausfielen, ergibt sich demnach, daß der Auszug aus der Rinderleber imstande ist, das zugefügte Coffein in dię durch ammoniakalische Silberlösung fällbaren Purinderivate überzuführen. Daß diese Purinderivate hauptsächlich aus Xanthin, ${ }^{1}$ ) Hypoxanthin, 1-Methylxanthin und Paraxanthin bestehen, habe ich durch besondere Versuche erwiesen. Da nun die Entmethylierung des Coffeins durch den Leberauszug bei Gegenwart von den Protoplasmagiften wie Toluol und Chloroform stattfindet und diese Wirkung bei demgekochten Leberauszug nicht zu beobachten ist, so glaube ich annehmen zu dürfen, daß ein Ferment in der Rinderleber vorhanden ist, das das Coffein abzubauen vermag. ${ }^{2}$ )

1) Ein Teil vom gefundenen Xanthin und das Hypoxanthin stammen sicherlich aus dem Lebergewebe.

2) Als diese Arbeit bereits zum Abschluß gebracht war, erschien eine Abhandlung von Alfred Schittenhelm (Zentralbl. f. d. gesamt. Physiol. u. Pathol. d. Stoffwechsels, 1908, Nr. 8, S. 28): Über Fermente im Lungengewebe. Dort ist angegeben, daß das der Pferdelunge zugesetzte Coffein entmethyliert wird. 